\title{
The Emergent Technological and Theoretical Paradigms in Education: The Interrelations of Cloud Computing (CC), Connectivism and Internet of Things (IoT)
}

\section{Mustafa Tuncay Sarıtaş}

Balikesir University, Necatibey Faculty of Education, Department of Computer Science and Instructional Technology, Soma cad., 10100, Balikesir, Turkey, tsaritas@balikesir.edu.tr

\begin{abstract}
With the rapid development and increase in Internet speed in network technology, communication and interaction with others, even with objects, as well as sharing and creation of knowledge is supported and facilitated more effectively than ever before. The characteristics of society are in an incessant change towards a more social, networked, and connected one. The education sector is also in a constant state of evolution, naturally as a result of emerging technologies and theories. Based on this fact, educational institutions, inevitably, have to transform their existing frameworks to promote learning and teaching in the $21^{\text {st }}$ Century. This paper introduces background and fundamentals about emerging technology paradigms - Cloud Computing (CC) and Internet of Things (IoT), and an emerging learning theory - Connectivism. The relationships between these three are investigated to provide insights and raise awareness on their rich potentials for and impacts on learning experiences.
\end{abstract}

Keywords: Cloud computing; connectivism; Internet of Things; education; learning

\section{Introduction}

Dramatic developments in information technology, and more specifically, the emergence of mobile devices (e.g., tablets and smart phones) and applications have transformed the way people attain, use, and save the information. Additionally, the vast expansion of wireless networks provides new opportunities and infrastructures for individuals and institutions to be easily able to utilize new IT resources more effectively and cost efficient. The amazing speed in the expansion of Internet-based information has created a circumstance, in other words, a challenge for organizations to have enough capacities and capabilities for service-oriented computing. Including, virtual, dynamically-scalable, manageable 
computing power, storage, platforms, and other services that can be delivered on demand to external customers over the Internet [15].

In recent years, "Cloud Computing (CC)" has emerged as a practical and assuring innovative solution to transforming traditional server infrastructure into a dynamic environment "for enabling convenient, on- demand network access to a shared pool of configurable computing resources (e.g., networks, servers, storage, applications, and services) that can be rapidly provisioned and released with minimal management effort or service provider interaction" [37, p590]. The concept of cloud computing has gained a significant amount of attention and has been defined with different perspectives.

Johnson, et al. [21, p36] defines cloud computing as:

...expandable, on demand services and tools that are served to the user via the Internet from specialized data centers and consume almost no local processing or storage resources. Cloud computing resources support collaboration, file storage, virtualization, and access to computing cycles, and the number of available applications that rely on cloud technologies.

According to Sultan and Sultan [25, p3], cloud computing is:

.... modality, that uses advances in ICTs such as virtualization and grid computing for delivering a range of ICT services through software, and virtual hardware (as opposed to physical) provisioned (by data centres owned and operated by cloud providers and/or end users) according to user demands and requirements and delivered remotely through public (e.g., Internet), private networks or a mix (i.e., hybrid) of the two delivery modes.

Using the main characteristics associated with the notion of cloud computing in the literature, Vaquero, et al. [23, p51] sums its definitions up as below:

Clouds are a large pool of easily usable and accessible virtualized resources (such as hardware, development platforms and/or services). These resources can be dynamically reconfigured to adjust to a variable load (scale), allowing also for an optimum resource utilization. This pool of resources is typically exploited by a payper-use model in which guarantees are offered by the Infrastructure Provider. 


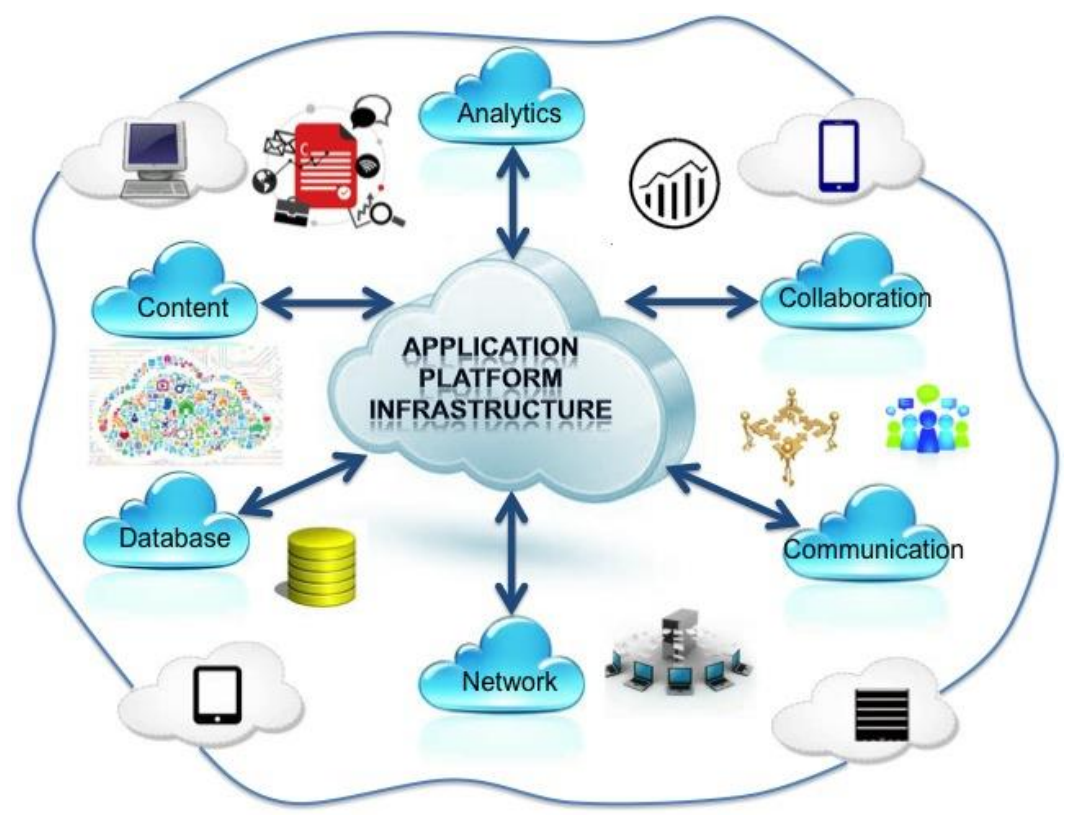

Figure 1

Cloud computing

The term "cloud" is used commonly as a metaphor of remote environments (e.g., Internet), which is illustrated with cloud-like images showing the complexity lying under full of servers providing different services through Internet connection. Understanding the cloud computing services could provide a better overview for what this new paradigm is all about. In general, $\mathrm{CC}$ services are categorized in three main types: Software as a Service (SaaS), Infrastructure as a Service (IaaS), and Platform as a Service (PaaS). Internet connection is the main requisite for three services. SaaS provides services (i.e., any application resides in the cloud) primarily for end-users who could access applications hosted in companies' servers. IaaS (also called utility computing) provides services (e.g., virtual machine instances, storage, and computation) generally for system administrators who could obtain general processing, storage, database management, and other applications through the network [30]. PaaS provides services (e.g., web hosting and data hosting services) mostly for developers who could design, build, and test applications within cloud infrastructure and then deliver those apps to end-users from the servers [30]. Table 1, below provides additional descriptions for three cloud services adopted from Sultan [24, p110]. 
Table 1

Cloud computing services

\begin{tabular}{|c|c|c|}
\hline User Levels & Service Type & Description \\
\hline $\begin{array}{l}\text { End-users } \\
\text { (individuals, } \\
\text { students, } \\
\text { administrators, } \\
\text { staff, etc.) }\end{array}$ & $\begin{array}{l}\text { Software as a } \\
\text { Service (SaaS) } \\
\text { Ex. Google } \\
\text { Docs, YouTube, } \\
\text { Facebook, } \\
\text { twitter, flickr, } \\
\text { and virtually } \\
\text { every other Web } \\
2.0 \text { application }\end{array}$ & $\begin{array}{l}\text { Under this service, applications are delivered through } \\
\text { the medium of the Internet as a service. Instead of } \\
\text { installing and maintaining software, you simply } \\
\text { access it via the Internet, freeing yourself from } \\
\text { complex software and hardware management. This } \\
\text { type of cloud service offers a complete application } \\
\text { functionality that ranges from productivity (e.g., } \\
\text { office-type) applications to programs such as those } \\
\text { for Customer Relationship Management (CRM) or } \\
\text { enterprise-resource management. }\end{array}$ \\
\hline $\begin{array}{l}\text { System } \\
\text { administrators, } \\
\text { researchers, } \\
\text { end-users } \\
\text { (individuals, } \\
\text { students, } \\
\text { administrators, } \\
\text { staff, etc.) }\end{array}$ & $\begin{array}{l}\text { Infrastructure } \\
\text { as a Service } \\
\text { (IaaS) } \\
\text { Ex. Data } \\
\text { storage/ hosting } \\
\text { and archiving/ } \\
\text { preservation }\end{array}$ & $\begin{array}{l}\text { Products offered via this mode include the remote } \\
\text { delivery (through the Internet) of a full computer } \\
\text { infrastructure (e.g., virtual computers, servers, } \\
\text { storage devices, etc.) }\end{array}$ \\
\hline Developers & $\begin{array}{l}\text { Platform as a } \\
\text { Service (PaaS) } \\
\text { Ex. Amazon's } \\
\text { S3 and EC2 } \\
\text { offerings }\end{array}$ & $\begin{array}{l}\text { To understand this cloud-computing layer, one needs } \\
\text { to remember the traditional computing model where } \\
\text { each application managed locally required hardware, } \\
\text { an operating system, a database, middleware, Web } \\
\text { servers, and other software. One also needs to } \\
\text { remember the team of network, database, and system } \\
\text { management experts that are needed to keep } \\
\text { everything up and running. With cloud computing, } \\
\text { these services are now provided remotely by cloud } \\
\text { providers. }\end{array}$ \\
\hline
\end{tabular}

\section{Cloud Computing in Education}

With the spread of information and communication technology, a variety of new learning situations have been proposed for learners, individually or in groups, who have the opportunity for carrying out learning activities and experiences whenever and wherever they want by switching from one learning scenario to another easily and quickly [14]. Cloud computing is not just an innovative information and communication technology that promises to bring various exciting services into our daily life. It is already a reality and paradigm in terms of its implementations in many sectors. The education sector is one of those in which cloud computing has already attracted institutions, schools, educators, and researchers. Due to its rich capability in delivering virtual computing environments of almost any scale, cloud computing offers new tools that foster best computing practices for easy 
sharing and mobility which improves productivity and expands collaboration in education. For instance, cloud computing provides engineering students with versatile and ubiquitous access to software commonly used in the field from any where, at any time [1].

The notion of providing computing-related services on the cloud (some free, some on a pay-as-you-go basis) offers numerous advantages and opportunities for data and software sharing, collaboration systems, and virtual learning environments. The cloud concept has imperative implications in virtual communication, collaboration, and learning contexts. This innovative communication and collaboration medium enables virtual communities of educators, researchers and practitioners to work in collaborative groups on the Internet with links to real time data, therefore, promoting a metacognitive approach in educational problems and practices via a dynamic research platform where data are dynamically stored, dynamically navigated, dynamically visualized, and so others [28]. From this perspective, $\mathrm{CC}$ has strong potential for fostering and facilitating social interactivity and metacognitive activities. Within a learning community, CC highly supports sharing of intellectual work, negotiation and co-creation of meanings or knowledge, research, reflection, evaluation, and application of newly constructed knowledge.

Stein, et al. [36, p241] addresses the educational benefits of Cloud computing for pedagogical aims in the following areas:

- Diversity of software applications: Cloud computing offers a costeffective way of circumventing such restrictions as reaching diverse learning applications for school and student computers, and of providing richer curricula to all school systems.

- Software license cost savings: Schools can share software applications legally and cost-effectively using the Cloud by purchasing a limited number of "seat" licenses and managing the concurrent use of the software.

- Security: Security of data and transactions are concerns for every user of networked computation. Cloud computing can be configured to meet the Internet Protection Act compliance policies put in place by schools. Cloud-based instructional software can be accessed and used securely by making schools' firewalls impervious to hackers.

- Extending machine life: Significant cost savings can be realized through Cloud computing by decreasing the replacement rate for student computers. Student access to software is made more equitable across socioeconomic differences since older, less powerful computers can remotely operate advanced software.

- Availability of broadband connectivity outside of school: Learning environments based on $\mathrm{CC}$ can specifically be designed to provide access to learning tools from anywhere at anytime. 
- Affordability of class time delivery: Face-to-face education employs strict time periods during which software must be available with minimal delay. Using CC platform, designed specifically for educational needs, block allocations (i.e., access to specified software and student registration for specific days and times) allow teachers to register their students and make pre-loaded software remotely available in less than a minute.

Cloud computing provides opportunities for teachers with quickly applicable educational applications and services that enrich the learning process based on individual performance data and learning style [1]. Teachers and students today are inundated with many low-cost or free cloud-computing applications offering SaaS that is accessible through diverse digital devices. Two of the most prevalent and free $\mathrm{CC}$ applications being adopted by educators are Google Apps for Education (including Gmail, Gdrive, Google Docs) and Microsoft's cloud service - Office 365 for Education (including Office, OneDrive, OneNote). Both of these applications provide educational institutions, teachers and students with platforms, which support dynamic learning experiences in and outside of the classroom, provide access to centralized information stores, and increase reporting consistency [1].

For instance, Lin, et al. [38], in their research study, proposed a cloud-based reflective learning environment, which was designed by using Google applications (Google Plus, Google Drive, and Google Site) as a set of teaching and learning tools. They conducted an experiment (including tests, questionnaires, and interviews) to evaluate the effectiveness of the proposed environment on the students' ability to develop and strengthen their reflection and motivation. According to the findings, students in the experimental group (i.e., those in the proposed cloud-based learning environment) showed higher learning motivation and reflection performance. The authors provided results that verified the cloudbased reflective learning environment supports instructors and students who effectively administered and conducted reflective learning activities during and after actual class sessions.

Sometimes, institutions choose a way of creating or joining a consortium where they define their position as a leader of innovation and progress in a certain field. The cloud-based consortiums particularly allow institutions to work collaboratively with other organizations and experts that could increase the availability of resources and speed of research activities. To give an example, the Open Cloud Consortium (OCC) (http://opencloudconsortium.org/) is "an open cloud computing infrastructure that facilitates community based science, in which researchers from member institutions, including the University of Chicago and Johns Hopkins University among others, can compile, analyze, and share huge data sets via the Open Science Data Cloud" [22, p10]. 


\section{Connectivism}

From an educational perspective, cloud-computing technology is commonly considered and practiced within the concept of virtual or online learning. $\mathrm{CC}$ is widely accepted to be suitable for online learning environment with its capabilities in facilitating information managing, data sharing, and collaborating, and so on. Considering today's students who are under the influence of Internet (those called Net Generation) and digital media and technologies (those called Digital Natives) have got unique habits, actions, learning styles, preferences, communication patterns within the ecology of networked content and communities. These students possess the skills of self-directing their learning progress, obtaining information from a variety of online resources, doing multitask quickly - sometimes simultaneously, and working in teams.

Therefore, along with the advancements in network technologies, educators have started to employ many different educational philosophies, strategies, and approaches for emerging needs and demands of students in the online milieu. Yet, there was a need to develop new pedagogical approaches, which take into consideration and explain new learning experiences specifically in a networked learning setting. The connectivism, introduced and advocated by George Siemens and Stephen Downes, was called "A Learning Theory for the Digital Age" [9]. George Siemens [9] defines connectivism as

...the integration of principles explored by chaos, network, and complexity and self-organization theories. Learning is a process that occurs within nebulous environments of shifting core elements - not entirely under the control of the individual. Learning (defined as actionable knowledge) can reside outside of ourselves (within an organization or a database), is focused on connecting specialized information sets, and the connections that enable us to learn more are more important than our current state of knowing.

George Siemens [11] explores some of the main categories and aspects of learning that are experienced today. According to Siemens, learning can be categorized as formal or structured learning; experience, games and simulation learning; mentoring and apprenticing; performance support; self-learning; communities of practice or learning communities; and informal learning. These seven learning categories are all interconnected with each other, which are driven by dimensions of learning (e.g., learning what, why, where), learning concepts (data, knowledge, meaning, understanding), conduits (e.g., language, media, technology), and filters for learning (e.g., values, beliefs, perspective). Change and transformation in knowledge with learner's intention to learn takes place in connected network of learning domains (see Figure 2). 


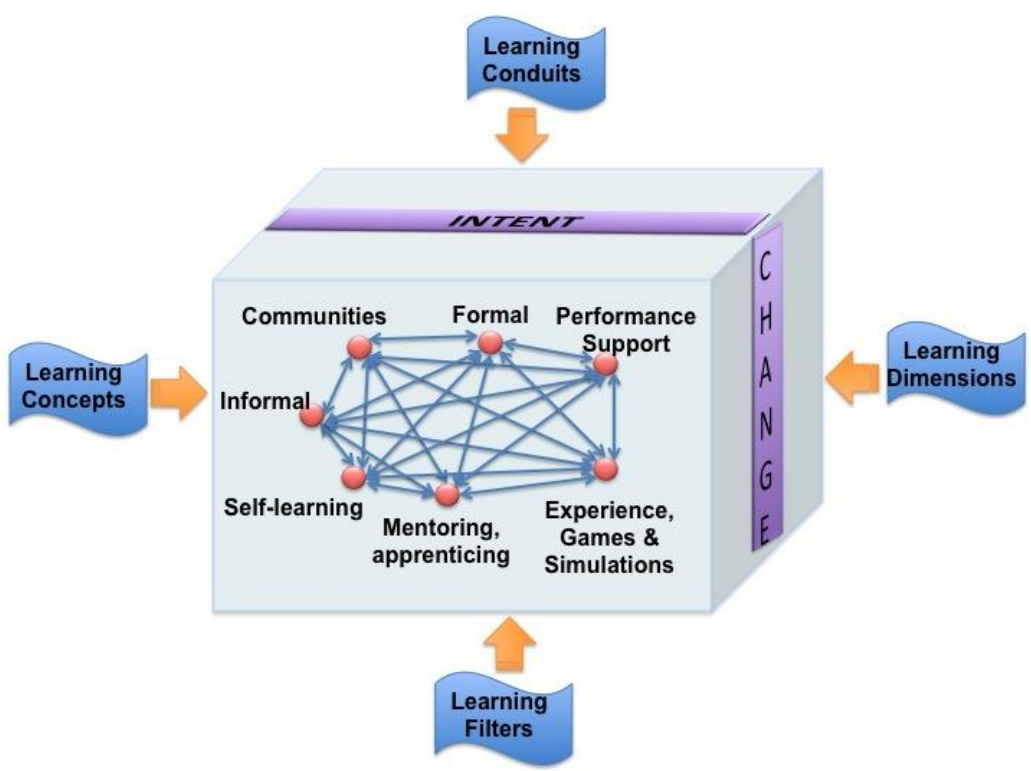

Figure 2

Learning Network

Connectivism is, simply, a learning theory grounded in the interactions within networks [34]. Stephen Downes [32] described it as, “... the thesis that knowledge is distributed across a network of connections, and therefore that learning consists of the ability to construct and traverse those networks." Siemens [9] identifies the fundamental principles of connectivism:

- Learning and knowledge rests in diversity of opinions

- Learning is a process of connecting specialized nodes or information sources

- Learning may reside in non-human appliances

- Learning is more critical than knowing

- Maintaining and nurturing connections is needed to facilitate continual learning

- Perceiving connections between fields, ideas and concepts is a core skill

- Currency (accurate, up-to-date knowledge) is the intent of learning activities

- Decision-making is itself a learning process. Choosing what to learn and the meaning of incoming information is seen through the lens of a shifting reality. While there is a right answer now, it may be wrong tomorrow due to alterations in the information climate affecting the decision. 
Downes [33] states that according to the connectivism: i) learning occurs as a distributed process in a network, based on recognizing and interpreting patterns; ii) the learning process is influenced by the diversity of the network, strength of the ties; iii) memory consists of adaptive patterns of connectivity representative of current state; iv) transfer occurs through a process of connecting; and v) best for complex learning, learning in rapidly changing domains. Knowledge is viewed in connectivism as a pattern of connectedness [13] (see Figure 3). Connectivism claims "knowledge - and therefore the learning of knowledge - is distributive that is not located in any given place (and therefore not 'transferred' or 'transacted' per se). It rather consists of the network of connections formed from experience and interactions with a knowing community" [31].

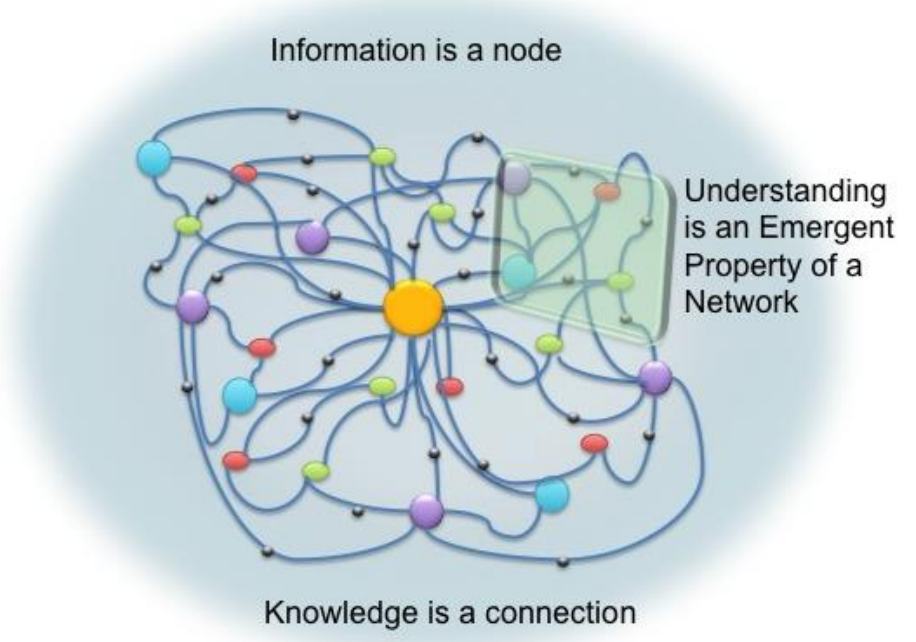

Figure 3

Knowledge in connectivism theory

Siemens [12] emphasized that, "Exponentially developing knowledge and complexification of society requires nonlinear models of learning (process) and knowing (state)." In brief, connectivism is described as, "the amplification of learning, knowledge, and understanding through the extension of a personal network" [8].

In a networked, technology-enriched arena, new instructional models and practices based on connectivism learning theory attracted a great interest of educators as well as researchers for promoting students' problem-solving skills [35], motivation in learning [7], and information literacy self-efficacy in a cloudbased virtual classroom [19]. The MOOC (which stands for massively open online courses), perhaps, best represents learning and teaching practices based on the 
concept of connectivism. The essence of the MOOC concept is that thousands or millions of participants from all over the world at any time could take a course in a networked environment (e.g., web course). One of the unique features of MOOCs is that a course (open and free of charge) is designed and/or contributed by a variety of experts, educators, and instructors supporting an expansive and a diverse set of contents for which the materials are not necessarily designed to go together, but become associated with each other [20]. MOOCs are one of the most prominent trends in online education since they support active and participative involvement within a learning community, where the contributions are shared and educational resources are distributed through an online platform to high volume learners. Cloud-based services (e.g., WikiSpaces, YouTube, and Google Hangouts, etc.) and the three major tools - Coursera, edX, and Udacity - are predominantly being used for offering MOOCs, for instance, to create discussion forums, share videos, assess learner performances and engage in all other learning and teaching activities in online ecosystem.

\section{Internet of Things (IoT)}

\subsection{Definition and Scope of the IoT}

The notion of connectivism, as stated above, supports the idea of learning that rests in the network of connected and relational patterns of actions and information. Over recent past years, the concept of connectedness has gained a growing interest in its place not only between human and human; or human and objects but also between/amongst objects - omnipresent connection of "objects" that intelligently connect and communicate internally or with others - with the ability of embedded smart devices, sensors, and networks. The term, Internet of Things (IoT) has been introduced to provide a better explanation about a network of connected objects that turn the information into actions in the physical world (e.g., mobile phones, smart houses, smart sensors, and Internet-enabled appliances, etc.).

Embedded chips, sensors, or tiny processors attached to an object allow helpful information about the object, such as cost, age, temperature, color, pressure, or humidity to be transmitted over the Internet. This simple connection allows remote management, status monitoring, tracking, and alerts... Many web tools allow objects to be annotated with descriptions, photographs, and connections to other objects, and other contextual information; the Internet of Things makes access to these data as easy as it is to use the web [21, p. 42]. 
The Internet of Things (IoT), also called the Internet of Everything, is considered the next evolution of Internet (see Figure 4); a new technology paradigm; and a next step in Information Industry. The evolution of Internet begins with a limited network (e.g., two-three computers connected), then moves towards to World Wide Web, then mobile devices with Internet connection appears, then social networks including people's identities and various information takes place, and finally the Internet of Things connecting every day objects to the Internet comes into our life [4].

IoT is an interdisciplinary field of which many alternative definitions have been introduced. The Internet of Things is defined as

A global network infrastructure, linking physical and virtual objects through the exploitation of data capture and communication capabilities. This infrastructure includes existing and evolving Internet and network developments. It will offer specific object-identification, sensor and connection capability as the basis for the development of independent cooperative services and applications. These will be characterised by a high degree of autonomous data capture, event transfer, network connectivity and interoperability [5, p10].

According to this definition, three categories of hardware technology are suggested, to realize IoT: i:) identification and data capture technologies forming the physical interface layer, ii) fixed, mobile, wireless and wired communication technologies, with associated interface support, for data and voice communications, and iii) network technologies (in combination with communication technologies) to facilitate grouping of supported Objects for application and service purposes [5, p16]. In addition to this, software, middleware components and associated protocols are necessary for linking objects and driving the hardware and service to establish a fully operational system or systems [5].

Another definition by Vermesan and Friess [26, pp7, 8] states that "Internet of Things (IoT) is a concept and a paradigm that considers pervasive presence in the environment of a variety of things/objects that through wireless and wired connections and unique addressing schemes are able to interact with each other and cooperate with other things/objects to create new applications/services and reach common goals."

Antoine de Saint-Exupery [2, p8] provides a definition, which covers a wideranging vision of IoT as "The Internet of Things allows people and things to be connected Anytime, Anyplace, with Anything and Anyone, ideally using Any Path/Network and Any Service. This implies addressing elements such as Convergence, Content, Collections (Repositories), Computing, Communication, and Connectivity in the context where there is seamless interconnection between people and things and/or between things and things so the $\mathrm{A}$ and $\mathrm{C}$ elements are present and addressed." 


\subsection{Impact of Internet of Things}

Internet of Things has been acknowledged as one of the emerging technologies in Information Technology. Through various enabling technologies such as nanoelectronics, sensors/actuators, cloud computing, IoT includes systems which bridge the gap between cyberspace and the physical world of real things [27]. As illustrated in Figure 5 below, IoT becomes a system consisting of different systems.

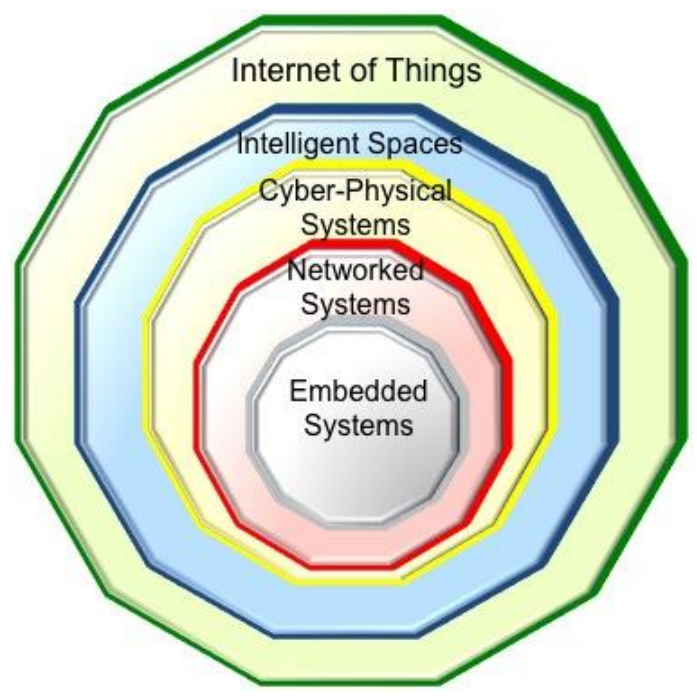

Figure 4

The relations of systems within IoT

With increasing levels of connectivity through IoT, smart life including smart cities, smart business, smart houses and so others will take place in our daily lives. It is predicted that there will be a connected society with 50 billion connected smart devices and approximately 7 connected devices per person around the world by 2020 [6]. This, therefore, shows us that new IoT products and services will grow exponentially in the following years. Due to this fact, major developed countries in the world consider and make investments on the IoT as an area of innovation and growth.

European Union is one of those where the number of IoT connections will increase from approximately 1.8 billion in 2013 (the base year) to almost 6 billion in 2020 [29]. Hence, according to the analysts, IoT revenues in the EU will be expected to increase from more than $€ 307$ billion in 2013 to more than $€ 1,181$ billion in 2020 [29]. Based on the research and predictive studies, in order to create a dynamic European IoT ecosystem, The Alliance for Internet of Things Innovation (AIOTI) (www.aioti.eu) was launched in 2015 by the European 
Commission. The AIOTI's goals are to provide and support interaction for future IoT research as well as innovation and standardization of policies among IoT stakeholders.

Within the market of the EU, the IoT is developing rapidly, generating multiple new services, and moving towards a more user-oriented perspective combining with Cloud Computing and Big Data. Aguzzi, et al. [29] provides a recommendation for EU's H2020 Program about prioritizing and increasing the investment(s) in the IoT and Cloud Computing combination for the development of technologies, research and innovation areas to take-up actions and accelerate the market and relevant ecosystem development.

Actually, there is a broad-spectrum expectation in many sectors in the world that new opportunities will get into our life from the combination of IoT and Cloud computing. Cloud computing is anticipated to be a vital part of the IoT. Applications of IoT will be almost anywhere producing an enormous amount of data, which have to be stored, accessed, processed, and transferred. Intelligent objects with sensors (of which processors become smaller, cheaper and more powerful), a truly revolutionary potential of IoT, will need a platform which can handle the speed and flow of the data accessible anywhere from any device. This is where cloud-computing platforms play their role of being an area of immense data storage and analytics. In addition, the interdependency of IoT and CC provides an effective opportunity especially for IoT developers who can use the Cloud as a development environment for IoT applications primarily by connecting devices through the Cloud [18]. According to IEEE [16],

The combination of cloud computing and IoT can enable ubiquitous sensing services and powerful processing of sensing data streams beyond the capability of individual "things", thus stimulating innovations in both fields. For example, cloud platforms allow the sensing data to be stored and used intelligently for smart monitoring and actuation with the smart devices. Novel data fusion algorithms, machine learning methods, and artificial intelligence techniques can be implemented and run centralized or distributed on the cloud to achieve automated decision-making.

\subsection{IoT in Education}

Internet-enabled appliances are coming into focus and utilization, more and more, every single day in the consumer industry. Finally, like many other emerging technologies transferred from industry sector and integrated into the world of education, IoT will find a place in various learning environments. It is forecasted that the IoT market in education and health will increase from $€ 22060$ in 2014 to $€ 66925$ in 2020 ( $€$ Million) in the European Union context [29]. Thus, it is strongly recommended to collaborate education and training actors in the field to 
develop appropriate curricula and main skills for adoption and integration of IoT into pedagogical situations [29].

Although concrete implementations of IoT, today, are difficult to find, its potentials in fostering learning attract educational institutions and educators. For instance, collaboration and engagement between teachers and students; and sharing and accessing digital content are easily encouraged and facilitated with the structure and features of IoT. "For instruction, IoT in higher education takes the form of blended learning models that integrate personalized materials and formative assessment technologies that deliver instant feedback. In this landscape, students will have the ability to monitor their own environment and collect realtime data for further study" [22, p47].

With the increase in connection speed to Internet, and reduction in equipment and software costs, IoT could offer better learning resources widely accessible, and real-time learning experiences that are immersive and interactive than many existing lectures and classes do so. For instance,

Archaeologists from the University of Bristol are embedding historical objects from the transatlantic slave trade for "Reflector," a project that aims to share stories through authentic pieces of history that would otherwise not be available to the masses. Every artifact has a story and presents an opportunity for learning about history and culture, and the Internet of Things is making it easier — and more automatic — to communicate them" [21, p43].

An empirical research study by Uzelac, et al. [3] was conducted to examine the impact of different parameters in the physical learning environment on students' focus based on the IoT concept. The researchers claimed that this was the first study in the literature providing insights in terms of the correlation between lecturer's voice features and students' focus on the lecture. 5 different parameters, namely, $\mathrm{CO} 2$ (CO2 sensor used), Temperature (Temperature sensor used), Air pressure (Air pressure sensor used), Humidity (Humidity sensor), Noise level (Noise level sensor on smartphone used), Lecturer's voice (Bluetooth headset connected to a netbook used) were measured in real classroom setting. The findings indicated that five uncorrelated parameters had significant impact on students' focus. The results also suggested that this kind of study presents a practical strategy for recognizing the students' focus during the lecture.

\section{Conclusions}

With today's ubiquitous computing technologies, an enormous amount of information has become available to an individual that can be stored, retrieved, accessed, and shared with others through networks at the point of need any time anywhere, even during mobility. Cloud computing, indeed, has entered in our life as an innovative technology that evokes a new kind of social phenomenon at different levels from posting a photo to Facebook or using the mobile Google 
Maps for driving directions to using software from any device and developing apps, products and activities. In addition, cloud computing enables a new kind of learning and teaching experiences. CC can offer a powerful platform and new computing tools for "a new instructional paradigm that makes a shift possible from the traditional practice of teaching as a private affair to a peer-reviewed transparent process, and makes it known how student learning can be improved generally, not only in one's own classroom but even beyond it" [28, p222].

Therefore, students, today, have the opportunity of accessing the knowledge by sharing distributed E-learning resources (OER) in cloud systems [1]. Although there is a growing interest in cloud computing for educational use, administrators, teachers and instructional designers must be careful to discern what truly improves and/or facilitates the learning and teaching process and what does not, with regard to CC. This technology creates teaching opportunities, but on the other hand, requires new instructional techniques and strategies that are effective for and go compatible with new networked learning activities.

Connectivism, a new learning theory proposed by Siemens (2005), can be considered an alternative and effective theory to support the learning and teaching through cloud computing technology. Since connectivism relies on sharing, making connections between people and ideas, it strongly encourages teachers to utilize CC tools. The principal pedagogical implication of connectivism is the development of knowledge through rich connections in a networked environment [10]. "Learning becomes the critical recognition of connections that change the network itself, simultaneously adding new connections, potentially in the absence of an instructor or authority" [17, p688].

The pace of change in our daily activities, in particular, communication, collaboration, and interaction with individuals in the society and objects around us is so rapid. The penetration of computing systems into society at every level is changing the way we see our relations, our life style and conditions, our work habits, and our interactions with individuals and objects. Perhaps, we are unaware of the fact that our lifestyle has already been replaced with another. We will experience this change even more with the adoption of Internet of Things, a recent phenomenon, which makes objects smarter, in that, they have the ability of sensing, actuation, communication with each other, collection of information from vast amounts of data and creation of new knowledge in order for people to take action(s) when needed.

This paper provides insights about emerging technology paradigms - Cloud Computing and Internet of Things - and an emerging learning theory Connectivism, which promise to provide innovative and alternative solutions in digital age. It is believed that the impact of those on many sectors will be experienced and visible and tangible in the near future. Education is, perhaps, one of the critical sectors among those because digital-born students are already actively using and becoming easily familiar with these emerging technologies in 
their social life. These are still early days, and educational institutions are at the beginning of a transition period facing many challenges in the adoption of technological, theoretical, and practical paradigms. It is strongly suggested that educational institutions should develop a comprehensive strategy including curricula, professional development of teachers, educational philosophy, data security, legal and political issues, and transformation of resources and infrastructure to be able to address the many unique challenges that lie ahead.

\section{References}

[1] A. Bouyer and B. Arasteh, "The Necessity of Using Cloud Computing In Educational System," Procedia - Social and Behavioral Sciences, Vol. 143, pp. 581-585, 2014

[2] A. De Saint-Exupery, "Internet of Things: Strategic Research Roadmap. The Cluster of European Research Projects," Tech. Rep., September, 2009 [Online] Available: http://www.internet-of-thingsresearch.eu/pdf/IoT_Cluster_Strategic_Research_Agenda_2009.pdf [Accessed: Jun. 04, 2015]

[3] A. Uzelac, N. Gligoric, S. Krco, “A Comprehensive Study of Parameters in Physical Environment that Impact Students' Focus during Lecture using Internet of Things," Computers in Human Behavior, Vol. 53, pp. 427-434, 2015

[4] C. Perera, A. Zaslavsky, P. Christen, D. Georgakopoulos, "Context Aware Computing for The Internet of Things: A Survey," IEEE Communications Surveys \& Tutorials, Vol. 16, No. 1, pp. 414-454, 2014 [Online] Available: http://ieeexplore.ieee.org/stamp/stamp.jsp?tp=\&arnumber=6512846 [Accessed: Jun. 07, 2015]

[5] Casagras, "RFID and the Inclusive Model for the Internet of Things," European Union, Brussels, Belgium, Rep. 216803, pp. 16-23, 2011

[6] D. Evans, "The Internet of Things-How the Next Evolution of the Internet is Changing Everything," Cisco Internet Business Solutions Group White Paper, 2011 [Online] Available: http://www.cisco.com/web/about/ac79/docs/innov/IoT_IBSG_0411FINAL. pdf [Accessed: Jun. 04, 2015]

[7] E. Trnova and J. Trna, J. "Motivational Effect of Communication Technologies in Connectivist Science Education," Online Journal of Communication and Media Technologies, Vol. 5, No. 3, pp. 107-119, 2015

[8] G. Siemens (2004) "Connectivism: A Learning Theory for the Digital Age". [Online] Available: http://www.elearnspace.org/Articles/connectivism.htm [Accessed: Jun. 07, 2015]

[9] G. Siemens, "Connectivism: A Learning Theory for the Digital Age," International Journal of Instructional Technology and Distance Learning, Vol. 2, No. 1, 2005 [Online] Available: 
http://www.itdl.org/Journal/Jan_05/article01.htm [Accessed: May. 07, 2015]

[10] G. Siemens (2006, Nov. 12) "Connectivism: Learning Theory or Pastime for the Self-Amused" Elearnspace [Online] Available: http://www.elearnspace.org/Articles/connectivism_self-amused.htm [Accessed: May. 07, 2015]

[11] G. Siemens (2007). "Professional and Personal Development" [Online] Available:

http://www.elearnspace.org/media/ProfessionalDevelopment/player.html [Accessed: May. 07, 2015]

[12] G. Siemens (2009) "elearnspace" [Online] Available: http://www.elearnspace.org/blog/. [Accessed: May. 07, 2015]

[13] G. Siemens (2011) "Re: Explanation Needed - Definition of Knowledge and Knowledge Models" [Online] Available: http://scope.bccampus.ca/mod/forum/discuss.php?d=16450 [Accessed: May. 07, 2015]

[14] G. Zurita, N. Baloian, J. Frez, "Using the Cloud to Develop Applications Supporting Geo-Collaborative Situated Learning," Future Generation Computer Systems, Vol. 34, pp. 124-137, 2014

[15] I. Foster, Z. Yong, I. Raicu, S. Lu, "Cloud Computing and Grid Computing 360-Degree Compared," in Grid Computing Environments Workshop, Nov 2008, pp. $1-10$

[16] IEEE. "Call for papers IEEE Internet of Things Journal Special Issue on Cloud Computing for IoT," IEEE Internet of things journal [Online] Available:

http://iotjournal.weebly.com/uploads/1/8/8/0/18809834/ieee_iot_journal_si_cloud_i ot_cfp_final.pdf [Accessed: Jun. 05, 2015]

[17] J. Barnett, V. McPherson, R. M. Sandieson, "Connected Teaching and Learning: The Uses and Implications of Connectivism in an Online Class," Australasian Journal of Educational Technology, Vol. 29, No. 5, pp. 685698, 2013

[18] J. Gubbi, R. Buyya, S. Marusic, M. Palaniswami, "Internet of Things (IoT): A Vision, Architectural Elements, and Future Directions," Future Generation Computer Systems, Vol. 29, pp. 1645-1660, 2013

[19] K. Kultawanicha, P. Koraneekija, J. Na-Songkhla, “A Proposed Model of Connectivism Learning Using Cloud-based Virtual Classroom to Enhance Information Literacy and Information Literacy Self-Efficacy for Undergraduate Students," Procedia - Social and Behavioral Sciences, Vol. 191, pp. 87-92, 2015 
[20] L. Johnson, S. Adams Becker, M. Cummins, V. Estrada, A. Freeman, H. Ludgate, "NMC Horizon Report: 2013 Higher Education Edition," The New Media Consortium, Austin, Texas, 2013 [Online] Available:http://www.nmc.org/pdf/2013-horizon-report-HE.pdf [Accessed: Jun. 03, 2015]

[21] L. Johnson, S. Adams Becker, V. Estrada, A. Freeman, "NMC Horizon Report: 2014 K-12 Edition," The New Media Consortium, Austin, Texas, 2014 [Online] Available: http://cdn.nmc.org/media/2014-nmc-horizonreport-k12-EN.pdf [Accessed: Jun. 03, 2015]

[22] L. Johnson, S. Adams Becker, V. Estrada, A. Freeman, "NMC Horizon Report: 2015 Higher Education Edition," The New Media Consortium, Austin, Texas, 2015 [Online] Available: http://cdn.nmc.org/media/2015nmc-horizon-report-HE-EN.pdf [Accessed: Jun. 07, 2015]

[23] L. M. Vaquero, L. M. Lindner, L. Rodero-Merino, J. Caceres, "A Break in the Clouds: towards a Cloud Definition," Computer Communication Review, Vol. 39, No. 1, pp. 50-55, 2009

[24] N. Sultan, "Cloud Computing for Education: A New Dawn?" International Journal of Information Management, Vol. 30, No. 2, pp. 109-116, 2010

[25] N. Sultan and Z. Sultan, "The Application of Utility ICT in Healthcare Management and Life Science Research: A New Market for a Disruptive Innovation?" In The European Academy of Management Conference, Rotterdam, The Netherlands, June 6-8, 2012 [Online] Available: http://www.researchgate.net/publication/277310972_The_application_of_ut ility_ICT_in_healthcare_management_and_life_science_research_a_new_ market_for_a_disruptive_innovation [Accessed: May. 09, 2015]

[26] O. Vermesan and P. Friess, Internet of Things: Converging Technologies for Smart Environments and Integrated Ecosystems. Aalborg, Denmark: River Publishers, 2013, pp. 7-151

[27] O. Vermesan, M. D. Nava, H. Grindvoll, "Driving Innovation through the Internet of Things - Distruptive Technology Trends," in Building the Hyperconnected Society: IoT Research and Innovation Value Chains, Ecosystems and Markets, O. Vermesan and P. Friess, Eds. Aalborg, Denmark: River Publishers, 2015, pp. 279-308

[28] P. Y. Thomas, "Cloud Computing," The Electronic Library, Vol. 29, No. 2, pp. 214-224, 2011

[29] S. Aguzzi, D. Bradshaw, M. Canning, M. Cansfield, P. Carter, G. Cattaneo, S. Gusmeroli, G. Micheletti, D. Rotondi, R. Stevens, "Definition of a Research and Innovation Policy Leveraging Cloud Computing and IoT Combination," European Commission, Directorate-General of Communications Networks, Content \& Technology, Brussels, Belgium, Rep. SMART number 2013/0037, 2014 [Online] Available: 
http://ec.europa.eu/newsroom/dae/document.cfm?doc_id=9472 [Accessed: Jul. 04, 2015]

[30] S. C. Park and S. Y. Ryoo, "An Empirical Investigation of End-Users' Switching toward Cloud Computing: A Two Factor Theory Perspective," Computers in Human Behavior, Vol. 29, pp. 160-170, 2013

[31] S. Downes (2006) "Learning Networks and Connective Knowledge" [Online] Available: http://itforum.coe.uga.edu/paper92/paper92.html [Accessed: May. 13, 2015]

[32] S. Downes (2007) "What Connectivism is" [Online] Available: http://halfanhour.blogspot.com/2007/02/what-connectivism-is.html [Accessed: May. 21, 2015]

[33] S. Downes (2010) "Connectivism and its Critics: What Connectivism is not" [Online] Available: http://www.downes.ca/post/53657 [Accessed: May. 21, 2015]

[34] S. Downes, Connectivism and Connective Knowledge: Essays on Meaning and Learning Networks. National Research Council (Canada) 2012 [Ebook]

Available: http://www.downes.ca/files/books/Connective_Knowledge-19May2012.pdf [Accessed: May. 16, 2015]

[35] S. Sitti, S. Sopeerak, N. Sompong, N, "Development of Instructional Model Based on Connectivism Learning Theory to Enhance Problem-Solving Skill in ICT for Daily Life of Higher Education Students," Procedia Social and Behavioral Sciences, Vol. 103, pp. 315-322, 2013

[36] S. Stein, J. Ware, J. Laboy, H. E. Schaffer, "Improving K-12 Pedagogy via a Cloud Designed for Education," International Journal of Information Management, Vol. 33, pp. 235-241, 2013

[37] V. H. Pardeshi, "Cloud Computing for Higher Education Institutes: Architecture, Strategy and Recommendations for Effective Adaptation," Procedia Economics and Finance, Vol. 11, pp. 589-599, 2014

[38] Y-T. Lin, M-L. Wen, M. Jou, D-W. Wu, "A Cloud-based Learning Environment for Developing Student Reflection Abilities," Computers in Human Behavior, Vol. 32, pp. 244-252, 2014 